\title{
Impact of universal disinfectant cap implementation on central line-associated bloodstream infections
}

Katreena Collette Merrill

Brigham Young University - Provo, katreena.merrill@byu.edu

Sharon Sumner

Lorraine Linford

Carrie Taylor

Christopher Macintosh

University of Utah

Follow this and additional works at: https://scholarsarchive.byu.edu/facpub

Part of the Other Nursing Commons

\section{Original Publication Citation}

Collette-Merrill, K., Sumner, S., Linford, L., Taylor, C. \& Macintosh, C. (2014). Impact of universal disinfectant cap implementation on central line-associated bloodstream infections. American Journal of Infection Control, 42(12), 1274-1277.

\section{BYU ScholarsArchive Citation}

Merrill, Katreena Collette; Sumner, Sharon; Linford, Lorraine; Taylor, Carrie; and Macintosh, Christopher, "Impact of universal disinfectant cap implementation on central line-associated bloodstream infections" (2014). Faculty Publications. 5251.

https://scholarsarchive.byu.edu/facpub/5251

This Peer-Reviewed Article is brought to you for free and open access by BYU ScholarsArchive. It has been accepted for inclusion in Faculty Publications by an authorized administrator of BYU ScholarsArchive. For more information, please contact ellen_amatangelo@byu.edu. 
Major article

\title{
Impact of universal disinfectant cap implementation on central line-associated bloodstream infections
}

\author{
Katreena Collette Merrill RN, PhD ${ }^{a}$, , Sharon Sumner RN, BS ${ }^{b}$, \\ Lorraine Linford RN, BS, CNSC ${ }^{c}$, Carrie Taylor RN, MS, CIC ${ }^{b}$, \\ Christopher Macintosh RN, BS ${ }^{\mathrm{d}}$

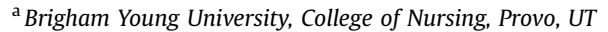 \\ ${ }^{\mathrm{b}}$ Infection Prevention, Intermountain Medical Center, Murray, UT \\ ${ }^{c}$ Intermountain Medical Center, Intravenous Therapy, Murray, UT \\ ${ }^{\mathrm{d}}$ School of Nursing, University of Utah, Salt Lake City, UT
}

\section{Key Words:}

Disinfection

Central line

Bloodstream

Compliance

Cost

Central line-associated bloodstream infection

Infection prevention

\begin{abstract}
Background: Central line-associated bloodstream infections (CLABSIs) result in increased length of stay, cost, and patient morbidity and mortality. One CLABSI prevention method is disinfection of intravenous access points. The literature suggests that placing disinfectant caps over needleless connectors decreases CLABSI risk.

Methods: A quasi-experimental intervention study was conducted in a $>430$-bed trauma I center. In addition to an existing standard central line bundle, a new intervention consisting of a luer-lock disinfectant cap with 70\% alcohol was implemented in all intravenous (IV) needleless connectors on patients with peripheral and central lines. Compliance to the disinfectant cap was monitored weekly. A generalized linear model using a Poisson distribution was fit to determine if there were significant relationships between CLABSIs and disinfectant cap use. Impacts on costs were also examined.

Results: The rate of CLABSI decreased following implementation of the disinfectant cap. The incidence rate ratios $(.577, P=.004)$ for implementing the disinfectant caps was statistically significant, indicating that the rate of patient infections decreased by $>40 \%$. Increased compliance rates were associated with lower infection rates. Disinfectant cap use was associated with an estimated savings of almost $\$ 300,000$ per year in the hospital studied.
\end{abstract}

Conclusions: Use of a disinfectant cap on IV needleless connectors in addition to an existing standard central line bundle was associated with decreased CLABSI and costs.

Copyright $\odot 2014$ by the Association for Professionals in Infection Control and Epidemiology, Inc. Published by Elsevier Inc. All rights reserved.
The magnitude of central line-associated bloodstream infections (CLABSIs) in the United States and abroad is staggering. It is estimated that 200,000-400,000 episodes of bloodstream infections occur annually in U.S. hospitals, resulting in increased length of stay, cost, and patient morbidity and mortality. ${ }^{1}$ Nearly 1 in every 10 hemodialysis catheters fail each month as a result of CLABSI, and the numbers are even greater in nontunneled catheters used in the acute care setting. Researchers report that mortality rates are between $12 \%$ and $25 \%$ from CLABSIs and estimate that annual costs associated with treatment exceed $\$ 2$ billion. ${ }^{2,3}$

\footnotetext{
* Address correspondence to Katreena Collette Merrill, RN, PhD, 432 Spencer Kimball Tower, BYU College of Nursing, Provo, UT 84602.

E-mail address: Katreena.merrill@byu.edu (K.C. Merrill).

Conflicts of interest: None to report.
}

The goal of hospital infection prevention programs is to eliminate CLABSI or decrease it as much as feasible given the patient population. ${ }^{3}$ Methods to reduce CLABSI consist of implementing several techniques referred to as a bundle of interventions that specify recommendations for proper insertion and appropriate handling of central lines. ${ }^{4}$ These multimodal approaches have been successful in decreasing CLABSI. .,6 $^{5}$

One specific aspect of the central line bundle is to minimize infection from intravenous (IV) access points. Most IV tubing contains several needleless connectors for the purposes of medication delivery and blood draws. Nurses access these needleless connectors several times a day, potentially increasing the possibility of contamination and subsequent infection.

To prevent infection in patients with IV access devices, the Centers for Disease Control and Prevention strongly recommend appropriate disinfectant of needleless connectors prior to access. ${ }^{3}$ 
Central Line-Associated Blood Stream Infections (CLABSI)

Rate per 1,000 central line days before and after implementation of a disinfectant cap

$1 / 1 / 2011-12 / 31 / 2012$

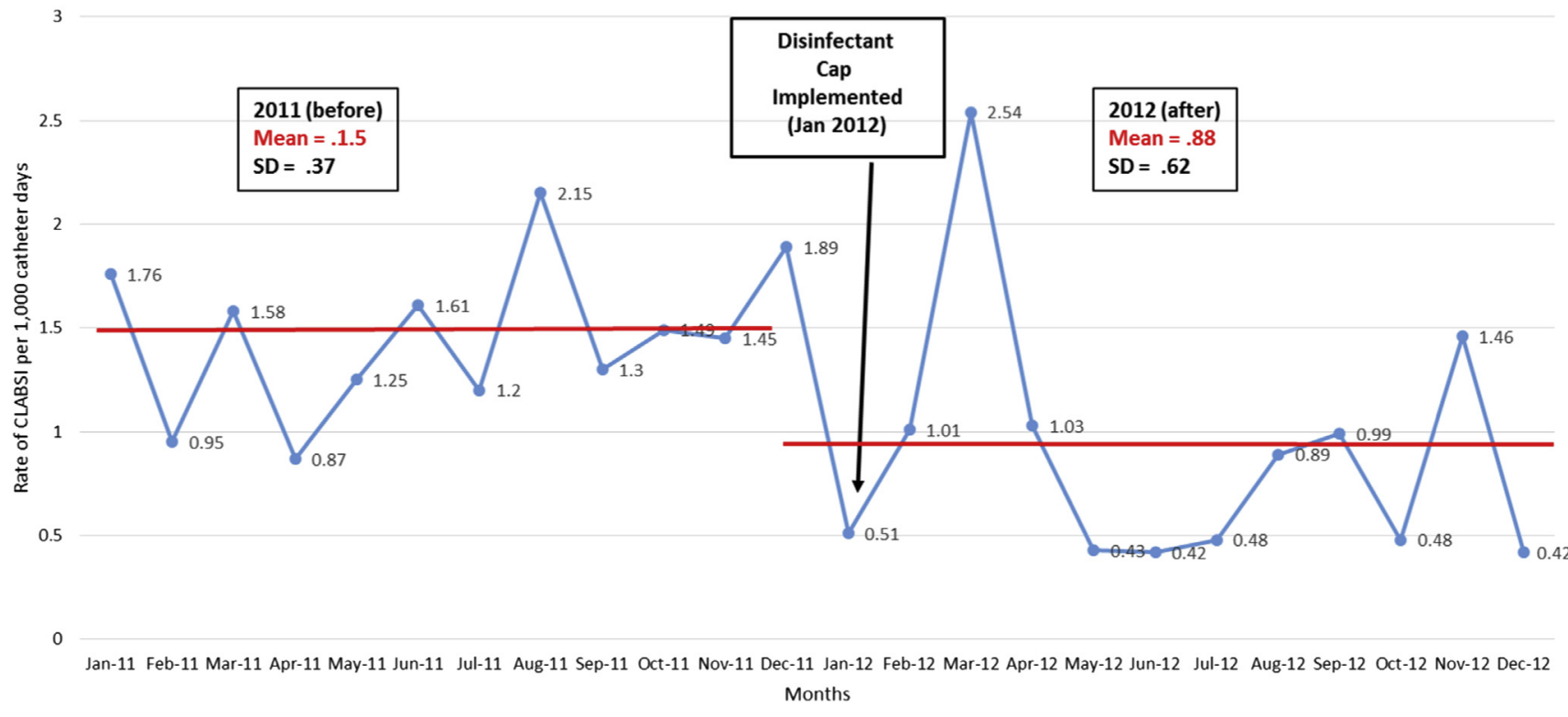

Fig 1. Effect of disinfectant cap on CLABSI rate. CLABSI, central line-associated bloodstream infection.

Although time and friction are recommended for disinfection, there are no specific recommendations on the amount of time needed to reach optimal disinfection (eg, 10, 15, or 30 seconds). Additionally, some argue that proper disinfection practices are difficult to maintain given the increased work load of nurses. ${ }^{7}$

In a 2006 in vitro study, researchers reported that the use of $70 \%$ alcohol prior to needleless connector entry is not sufficient protection against microbial contamination; therefore, the use of a disinfectant cap was recommended. ${ }^{8}$ The literature suggests that a disinfectant cap placed over IV needleless connectors decreases colonization on the connector, therefore lowering the risk of CLABSI. ${ }^{9}$ Another quality improvement study found that the use of a closed luer-lock disinfectant cap significantly decreased hemodialysis catheter infections in pediatric patients. ${ }^{10}$ In a more recent study, the implementation of a disinfectant cap decreased line contamination, bacterial density, and CLABSI rates. ${ }^{11}$ Based on these promising results, additional research is needed to test the generalizable effectiveness of widespread implementation of a disinfectant cap to decrease or eliminate CLABSI.

The purpose of this study is to analyze the effect of universal IV needleless connector disinfectant cap implementation on the rate and type of CLABI and estimated costs in a large tertiary care center using a standard central line bundle. Additionally, the relationship between disinfectant cap compliance and CLABSI rates is explored.

\section{METHODS}

\section{Setting and design}

This quasi-experimental short interrupted time series ${ }^{12}$ intervention study was conducted in a 430-bed tertiary care trauma I center in the U.S. Mountain West. A luer-lock disinfectant cap with $70 \%$ alcohol was implemented in all patients (newborn to adults) with peripheral and central lines residing on 13 inpatient units at 1 hospital beginning in January 2012. Excluded from this study were patients in the emergency department, ambulatory care, surgical services, labor and delivery, and well-baby nursery and patients who were postpartum.

\section{Intervention}

The disinfectant cap (Curos Disinfecting Port Protector, Curos, San Diego, CA) is a plastic-threaded device that contains $70 \%$ isopropyl alcohol. This device received a $510(\mathrm{k})$ clearance from the U.S. Food and Drug Administration for 1 -time use. ${ }^{13}$ It is effective within 3 minutes of application and may be used up to 7 days. Prior to implementation, the hospital product review committee and the institutional review board approved the use of the product for this research study. Nursing staff were introduced to the proper use of the cap through onsite training by the vendor, an education fact sheet, or required online training. Staff also participated in individual 1-on-1 follow up.

In this study, the disinfectant cap was placed universally on all IV needleless connectors (central, peripheral, and IV tubing) when the connectors were not in use. Compliance to the disinfectant cap was monitored weekly and reported to each unit to encourage use of the disinfectant cap.

\section{Data collection and analysis}

\section{Compliance}

Following implementation of the disinfectant cap, compliance was determined by audits conducted 1-2 times per week beginning in February 2012 and lasting throughout the study period. The number of disinfectant caps present was divided by the number of total available needleless connectors to result in an overall compliance rate per central line patient. The data were then aggregated to the nursing department level and reported to each manager as a weekly nursing department compliance rate. 
Table 1

Disinfectant cap intervention, CLABSI rates, and compliance parameter estimates

\begin{tabular}{llccccc}
\hline Model & \multicolumn{1}{c}{ Parameter } & \multicolumn{1}{c}{$\mathrm{B}$} & \multicolumn{1}{c}{$\mathrm{SE}$} & \multicolumn{1}{c}{$P$} & \multicolumn{1}{c}{ IRR } & 95\% CI for IRR \\
\hline CLABSI & Intercept & -2.161 & 0.073 & $.000^{*}$ & 0.115 & $.100-.133$ \\
Intervention & Intervention $=1$ & -0.55 & 0.193 & $.004^{*}$ & 0.577 & $.396-.842$ \\
CLABSI & Intercept & -2.19 & 0.0877 & $.000^{*}$ & 0.112 & $.094-.133$ \\
Compliance & Compliance \% & -0.073 & 0.0228 & $.001^{*}$ & 0.93 & $.889-.972$ \\
\hline
\end{tabular}

CI, confidence interval; CLABSI, central line-associated bloodstream infection; IRR, incidence rate ratio.

*Statistically significant result.

\section{CLABSI}

The presence of CLABSI was defined as "a primary laboratory confirmed bloodstream infection in a patient with a central line at the time of (or within 48 hours prior to) the onset of symptoms and the infection is not related to an infection from another site." ${ }^{3}$ All positive blood cultures in the hospital were reviewed to determine if they met the definition for CLABSI. The rate of CLABSI was calculated per 1,000 central line catheter days.

\section{Impact of CLABSI}

Cost, estimated case fatality, and additional ICU length of stay were estimated to represent the impact of CLABSI. Cost of CLABSI was estimated at $\$ 25,000$ per case, a low estimate based on the literature, which estimates CLABSI results at $\$ 25,000-\$ 55,000$ per incident. $^{2,14}$ Estimated case fatality was based as $6 \%$, with 4 additional days in the hospital; both are low estimates from the CDC literature. $^{2,14}$ The number of CLABSI cases was multiplied by the estimated cost, mortality, and length of stay before and after implementation of the disinfectant cap. The cost of implementation supplies (disinfectant cap and no-port tubing) were also taken into consideration.

\section{Analysis}

The rate of CLABSI and costs were compared for 12 months before (2011) and after the intervention (2012). Data were analyzed using IBM SPSS version 22.0 (SPSS Inc, Chicago, IL). ${ }^{15}$ A generalized linear model using a Poisson distribution was fit to determine if there was a significant difference in CLABSI rates following implementation of the disinfectant cap. The model was adjusted for the number of line days per patient.

\section{RESULTS}

The rate of CLABSI per 1,000 central line days decreased following implementation of the disinfectant cap (before implementation: mean $\pm \mathrm{SD}, 1.5 \pm .37$ ) (after implementation: mean \pm SD, $.88 \pm .62$ ) (Fig 1). The robust estimator option was used as the deviance statistic (.679) and was somewhat $<1$ as assumed when using the Poisson distribution. ${ }^{16}$ The incidence rate ratio (IRR $=.577, P=.004)$ for implementing the disinfectant caps was statistically significant, indicating that the rate of patient infections decreased by $>40 \%$ with the use of the disinfectant cap. Parameter estimates are reported in Table 1.

Before implementation (2011), the total estimated cost for CLABSI for the hospital in this study was $\$ 1$ million per year. Following implementation of the disinfectant cap (2012), the cost of CLABSI was estimated at $\$ 575,000$ per year. After subtracting the cost of supplies, this resulted in an estimated annual savings of $\$ 282,840$ (Table 2). We also estimated that implementation of the disinfectant cap resulted in a decrease of 68 patient hospital days and prevented one death.
Table 2

Effect of disinfectant cap on central line-associated bloodstream infection costs

\begin{tabular}{lccc}
\hline & $\begin{array}{c}\text { Estimated costs in } \\
2011 \text { (before } \\
\text { implementation) }\end{array}$ & $\begin{array}{c}\text { Estimated costs in } \\
2012 \text { (following } \\
\text { implementation) }\end{array}$ & $\begin{array}{c}\text { Estimated cost } \\
\text { avoidance }\end{array}$ \\
\hline $\begin{array}{c}\text { Supplies } \\
\text { Annual BSI cost } \\
\text { (estimated at } \\
\begin{array}{l}\$ 25,000 \text { per } \\
\text { episode) }\end{array}\end{array}$ & $\begin{array}{c}\$ 1,050,000 \\
\$ 192,160\end{array}$ & $\begin{array}{c}\$(192,160) \\
\$ 475,000\end{array}$ \\
Totals & $\$ 1,050,000$ & $\$ 575,000$ & \\
\hline
\end{tabular}

$B S I$, bloodstream infection; $N A$, not applicable.

\section{DISCUSSION}

CLABSI is a significant health care-acquired infection; however, CLABSI is preventable. Improvement efforts were successful by creating a feedback loop to improve practice and foster innovation. Nurses received compliance reports from infection preventionists, which resulted in increased compliance. A notable finding in this study is that a $10 \%$ increase in compliance resulted in a $7 \%$ drop in infection (IRR $=.93 ; 95 \%$ confidence interval, .889-.972), as seen in Table 1. In addition, during implementation, nurses expressed frustration that uncovered needleless connectors high in the IV tubing that were never used were counted against compliance rates. As a result of this feedback, the hospital purchased no-port tubing, further protecting the patient from potential entries into the system. Creating a feedback loop proved to be an important strategy for increasing compliance, thereby preventing infection as is supported by the quality improvement plan-do-check-act cycle. ${ }^{17}$

Another important finding in this study is the relationship with implementation of a disinfectant cap and a significant decrease in CLABSI rates. These findings are timely because they support the growing body of knowledge that disinfectant caps are one method to prevent CLABSI. ${ }^{8,11,18}$ This study also showed that disinfectant caps are one aspect of aseptic techniques for preventing CLABSI that is easier to monitor for compliance than other infrequent procedures (eg, dressing change, line insertion) that are not readily apparent with visual surveillance.

The treatment of CLABSI varies by patient; however, most clinicians agree that CLABSI results in an increased hospital length of stay and, in some cases, death. This study used low estimations for length of stay and mortality; even so, implementation of the disinfectant cap might have decreased hospital stays by 1 day per week and eliminated 1 death during the study period. Using the CLABSI opportunity estimator published by Johns Hopkins Quality Safety Research Group would have doubled these numbers. ${ }^{19}$

Although improved patient outcomes alone should be a sufficient motivator to prevent health care-acquired infections, it is often the financial impact that receives the most attention. In a comparative study, the costs of hospitalized patients who acquired CLABSI were matched with similar patients who did not experience CLABSI. They concluded that the occurrence of CLABSI resulted in a significant impact on hospital operating costs. ${ }^{6}$

When infections are prevented, the impact is calculated in terms of cost avoidance. After considering the costs of purchasing disinfectant caps and no-port tubing, this current study also identified a significant cost avoidance by decreasing CLABSI. Cost avoidance is considered soft money and can be difficult to track and justify. It is important to emphasize cost avoidance when considering the investment in the purchase of disinfectant caps and no-port tubing. This study was successful in part because of the support of hospital administration and the cooperation of the hospital products committee who understood the overall patient safety ramifications and cost savings. 
Disinfection of the IV needleless connectors is only one aspect of CLABSI prevention. Other aspects of prevention (eg, insertion, dressing changes) are important to consider for those striving for zero infection rates. Unfortunately, compliance to these important aseptic techniques might be more difficult to measure than compliance to a disinfectant cap.

\section{LIMITATIONS}

There are some limitations to this study. Ongoing education was implemented simultaneously by the hospital, which might have affected the CLABSI rates. Further, use of the disinfectant cap may have resulted in an increased vigilance to compliance to the central line bundle, which was not measured as part of the study. Cost estimates were based on projections reported in the literature. Although costs were about 50\% lower than other reports, they might not reflect true costs.

\section{CONCLUSION}

CLABSI is a serious, preventable, health care-acquired infection. This study found a relationship between implementation of a disinfectant cap and reduced rates of CLABSI, cost, length of stay, and mortality. As this increasing body of knowledge becomes available, infection preventionists might need to consider that some time honored traditions (eg, scrub the hub) should now be replaced with new product technology. Further, this study found success in implementation of a quality improvement feedback loop and found that compliance rates resulted in prevention of CLABSI. This improvement model might prove successful in other infection prevention campaigns.

\section{References}

1. Shekelle PG, Wachter RM, Pronovost PJ, Schoelles K, McDonald KM, Dy SM, et al. Making health care safer II: an updated critical analysis of the evidence for patient safety practices. Agency for Healthcare Research and Quality Web site. 2013. Available from: http://www.ahrq.gov/research/findings/evidence-basedreports/ptsafetyuptp.html. Accessed May 22, 2014.

2. Sagana R, Hyzy RC. Achieving zero central line-associated bloodstream infection: rates in your intensive care unit. Crit Care Clin 2013;29:1-9.

3. O'Grady NP, Alexander M, Burns LA, Dellinger P, Garland J, Heard SO, et al. Guidelines for prevention of intravascular catheter-related infections, 2011.
Centers for Disease Control and Prevention. Available from: http://www.cdc. gov/hicpac/pdf/guidelines/bsi-guidelines-2011.pdf. Accessed April 23, 2014.

4. Marschall J, Mermel LA, Classen D, Arias KM, Podgorny K, Anderson DJ, et al. Strategies to prevent central line-associated bloodstream. Infect Control Hosp Epidemiol 2008;29(Suppl 1):S22-30.

5. Jeffries HE, Mason W, Brewer M, Oakes KL, Muñoz EI, Gornick W, et al. Prevention of central venous catheter-associated bloodstream infections in pediatric intensive care units: a performance improvement collaborative. Infect Control Hosp Epidemiol 2009;30:645-51.

6. Shannon RP, Patel B, Cummins D, Shannon AH, Ganguli G, Lu Y. Economics of central line-associated bloodstream infections. Am J Med Qual 2006;21(Suppl): 7S-16S.

7. Doellman D. The role of technology in reducing risks associated with CRBSI. Ivera Medical Corporation Web site. Available from: www.iveramed.com (2011). http://www.curos.com/wp-content/uploads/CRBSI-White-Paper_-DarcyDoellman.pdf. Accessed May 22, 2014.

8. Menyhay SZ, Maki DB. Disinfection of needless catheter connectors and access ports with alcohol may not prevent microbial entry: the promise of a novel antiseptic-barrier cap. Infect Control Hosp Epidemiol 2006;17:23-7.

9. Oto J, Imanaka H, Konno M, Nakataki E, Nishimura M. A prospective clinical trial on prevention of catheter contamination using the hub protection cap for needleless injection device. Am J Infect Control 2011;39:309-13.

10. McAfee N, Seidel K, Watkins S, Flynn JT. A continuous quality improvement project to decrease hemodialysis catheter infections in pediatric patients: use of a closed luer-lock access cap. Nephrol Nurs J 2010;37:541-4.

11. Wright MO, Tropp J, Schora DM, Dillon-Grant M, Peterson K, Boehm S, et al. Continuous passive disinfection of catheter hubs prevents contamination and bloodstream infection. Am J Infect Control 2013;4:33-8.

12. Shadish WR, Cook TD, Campbell DT. Experimental and quasi-experimental designs for generalized causal inference. Boston [MA]: Houghton Mifflin; 2002.

13. Food and Drug Administration. Ivera Medical Curos 510(k) notification. (2012) Available from: http://www.accessdata.fda.gov/cdrh_docs/pdf11/K111992.pdf. Accessed May 22, 2014.

14. Latif A, Majid H, Mahmood F, Pronovost P, Dowdy D. Cost effectiveness of reducing CLABSI in the limited resource setting of developing countries. Crit Care Med 2013;41(Suppl):s122-3.

15. IBM Corp. IMB SPSS statistics for Windows, Version 22.0. Armonk [NY]: IBM Corp; 2013.

16. Hilbe JM. Negative binomial regression. 2nd ed. New York [NY]: Cambridge University Press; 2011.

17. Blot K, Bergs J, Vogelaers D, Blot S, Vandijck D. Prevention of central-line associated bloodstream infections through quality improvement interventions: a systematic review and meta-analysis. Clin Infect Dis 2014;59: 96-105.

18. Sweet MA, Cumpston A, Briggs F, Hamadani CM. Impact of alcoholimpregnated port protectors and needleless neutral pressure connectors on central line-associated bloodstream infections and contamination of blood cultures in an inpatient oncology unit. Am J Infect Control 2012;40: 931-4.

19. Johns Hopkins Medicin, Armstrong Institute for Patient Safety and Quality. CLABSI toolkit. 2008; Available from: http://www.hopkinsmedicine.org/ armstrong_institute/improvement_projects/stop_bsi/clabsi_toolkit.html. Accessed May 20, 2014. 